\title{
Application of Modified Taguchi Method in Process parameter Selection of the Resistance Spot Welding
}

\author{
Dr. V. V. Satyanarayana ${ }^{1}$, K. Rajesh Kumar ${ }^{2}$, V. Ramalingeswar Rao ${ }^{3}$ \\ ${ }^{1}$ Professor, Department of Mechanical Engineering in Vidya Jyothi Institute of Technology, Telengana, India \\ ${ }^{2}$ Associate Professor, Department of Mechanical Engineering in Vidya Jyothi Institute of Technology, Telengana, India \\ ${ }^{3}$ Associate Professor, Department of Mechanical Engineering in Vidya Jyothi Institute of Technology, Telengana, India
}

\begin{abstract}
Dissimilar stainless steel welding of AISI304 and AISI430 is carried out by resistance spot welding process. The material possesses different characteristics which include chemical, metallurgical, thermal and mechanical properties. These differences pose lots of problems in fusion welding process. Hence resistance welding process is opted for their joining. The design of experiments is done as per Taguchi technique and $\mathrm{L}_{8} \mathrm{OA}$ is chosen accordingly. The evaluation of mechanical properties is carried by attributing weitages to the responses and made into a single response. The modified Taguchi method is applied for analysis and identified the optimal values.
\end{abstract}

Keywords: Spot Welding, Taguchi method, Dssimilar Weld, Anova Response, AISI304, AISI430

\section{Introduction}

The quality of joints made in welding engineering has become more and more important to satisfy the increasing demands of sophisticated component performance and reliability. It depends on mechanical, metallurgical, thermal and chemical properties of the mating parts.

Ferritic stainless steels exhibit superior stresscorrosion cracking and pitting corrosion resistance compared to austenitic stainless steel [1].In some reduction retorts the austenitic stainless steel is cladded with ferritic stainless steel for prevention of nickel leaching by liquid magnesium. Austenitic stainless steels when used in cryogenic and corrosive environment, the quantity of ferrite in the weld must be controlled to avoid property degradation during service [2].Welding of ferritic to austenitic stainless steel is considered to be major problem due to difference in coefficient of thermal expansion, thermal conductivity leads to crack formation at interface; Also hard and soft zones formed close to weld interface, consequently leads to failure in service [3].The hardness and residual stresses are high on the austenitic stainless steel side of the interface in the frictional welding of austenitic-ferritic stainless steel dissimilar joints [4].

\section{Experimental Procedure}

\subsection{Parent Metals}

In this study AISI304 austenitic stainless steel and AISI430 Ferritic stainless steel are employed. The chemical composition and mechanical properties of these metals are given in Table-1.The thickness of ferritic stainless steel sheet is $0.6 \mathrm{~mm}$ while that of the austenitic stainless steel is $1.2 \mathrm{~mm}$.

Table 1: Chemical composition \& Mechanical Properties

\begin{tabular}{|c|c|c|c|c|c|c|c|c|c|c|}
\hline Metal & $C$ & $S i$ & $M n$ & $C r$ & $S$ & $P$ & $N i$ & $U T S(M P a)$ & $\%$ Elongation & $H_{V}$ \\
\hline AISI430 & 0.06 & 0.4 & 0.4 & 17.0 & 0.03 & 0.04 & - & 488 & 28 & 190 \\
\hline AISI304 & 0.06 & 0.3 & 1.3 & 18.4 & 0.28 & 0.40 & 8.17 & 600 & 58 & 220 \\
\hline
\end{tabular}

\subsection{Resistance Spot Welding}

The sheet metals to be joined are held between two electrodes of the spot welding machine under pressure and high amperage is sent. The coalescence is produced, in relatively small area equal to the cross sectional area of the electrode, by the heat obtained with the resistance between the faying surfaces. Tensile strength increases rapidly with increasing current density; however excessive current will cause molten metal expulsion, weld cracking and burn off. Similarly some minimum time is required to reach melting temperature at suitable current density. Excessive long weld time will have the same effect as amperage on base metal [5].The amount of heat generated is a function of current, resistance between sheets and weld time of the process. The spot weld joints are made by trial runs and parameters range is identified. The resistance spot welding machine employed for experimentation is shown in Figure-1.

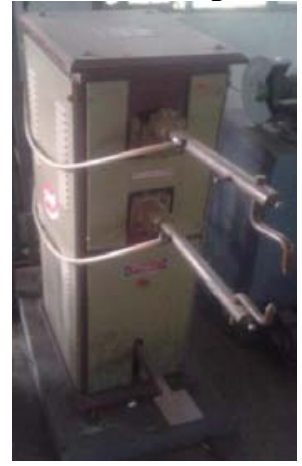

Figure 1: Resistance Spot Welding Machine 


\section{International Journal of Science and Research (IJSR) \\ ISSN (Online): 2319-7064 \\ Index Copernicus Value (2013): 6.14 | Impact Factor (2014): 5.611}

\subsection{Design of Experiments}

Use of statistical technique in process parameter selection has been used to study the effects on a response. To study the effect of the process parameters with a small number of experiments Taguchi Technique is used. It is well known that Taguchi Technique has been designed to optimize a single quality characteristic, but to consider several quality characteristics together in the selection of process parameters, modified Taguchi method is used [6].The welding process parameters are given in Table -2. For experimentation $\mathrm{L}_{8}$ orthogonal array of Taguchi is selected [7] and is given in Table-3.

Table 2: Process Parameters

\begin{tabular}{|c|c|cc|}
\hline Level & Unit & Low & High \\
Parameters & & 1 & 2 \\
\hline Weld current $\mathrm{x}_{1}$ & $\mathrm{Amp}$ & 8000 & 12000 \\
\hline Weld Time $\mathrm{x}_{2}$ & $\mathrm{~Hz}$ & 20 & 30 \\
\hline Electrode Force $\mathrm{x}_{3}$ & $\mathrm{KN}$ & 2 & 4 \\
\hline
\end{tabular}

Table 3: $\mathrm{L}_{8}$ Orthogonal Array

\begin{tabular}{|c|c|c|c|}
\hline Run & $\mathbf{X}_{\mathbf{1}}$ & $\mathbf{X}_{\mathbf{2}}$ & $\mathbf{X}_{\mathbf{3}}$ \\
\hline $\mathbf{1}$ & 1 & 1 & 1 \\
\hline $\mathbf{2}$ & 1 & 1 & 2 \\
\hline $\mathbf{3}$ & 1 & 2 & 1 \\
\hline $\mathbf{4}$ & 1 & 2 & 2 \\
\hline $\mathbf{5}$ & 2 & 1 & 1 \\
\hline $\mathbf{6}$ & 2 & 1 & 2 \\
\hline $\mathbf{7}$ & 2 & 2 & 1 \\
\hline $\mathbf{8}$ & 2 & 2 & 2 \\
\hline
\end{tabular}

Despite the differential thickness of sheets employed for making joints the contact electrodes are of the same size on both sides. A typical dissimilar metal Lap joint made is shown in Figure-2.

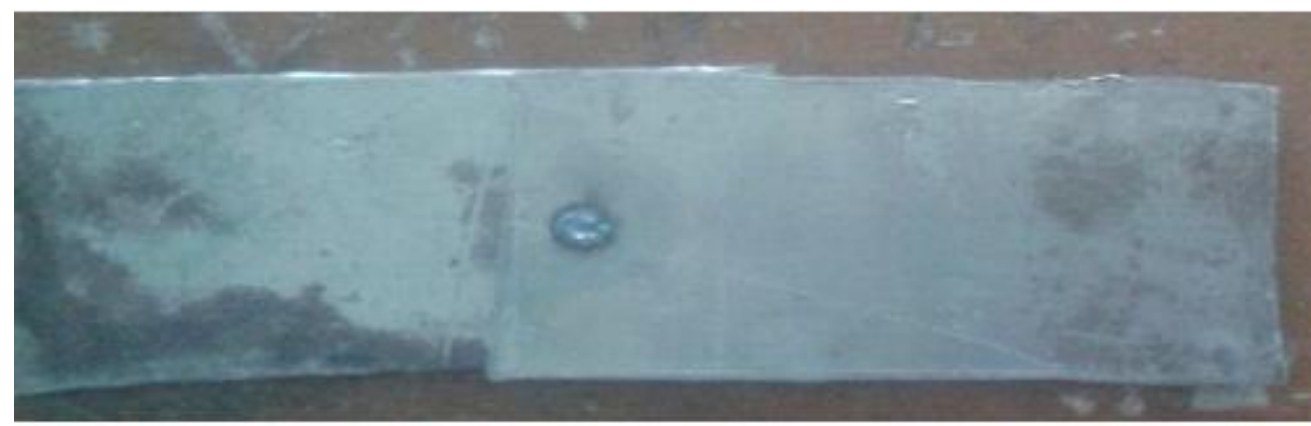

Figure 2: Dissimilar Metal Lap Joint

\subsection{Mechanical Property Evaluation}

The joints produced are subjected to property evaluation. Tensile shear test is conducted on Universal Tensile Testing Machine. Micro hardness tests were carried out using a Vickers digital micro hardness tester. The loads were 100 gms for all the samples applied for the duration of 10 seconds while measuring the hardness. The hardness was measured on both the sides of the joint as shown in the schematic sketch of the sample given in Figure-3.

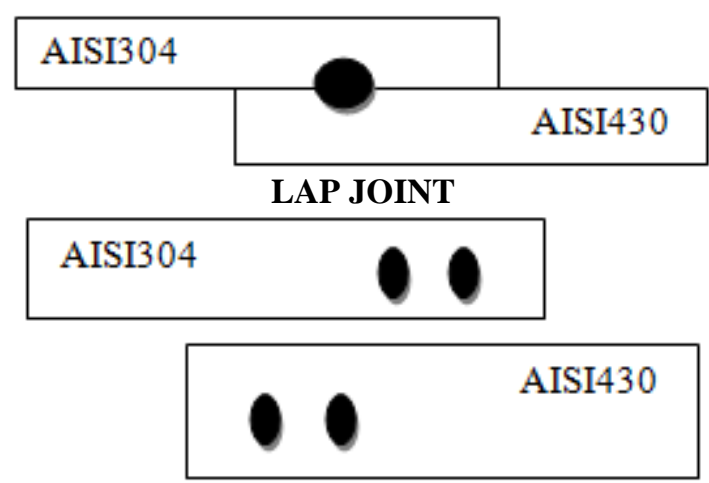

Figure 3: Schematic Sketch of Hardness Traverse

\subsection{Results and Discussion}

The experiments are conducted in accordance with orthogonal array and the results were tabulated in Table- 4 .
Table 4: Tensile shear strength and Micro Hardness

\begin{tabular}{|c|c|c|c|c|c|}
\hline \multirow{2}{*}{ Run } & \multirow{2}{*}{$\begin{array}{c}\text { Tensile } \\
\text { Shear }\end{array}$} & \multicolumn{4}{|c|}{ Micro Hardness } \\
\cline { 3 - 6 } & Strength(N) & On Weld & $\begin{array}{c}\text { Adjacent to } \\
\text { Weld }\end{array}$ & On Weld & $\begin{array}{c}\text { Adjacent to } \\
\text { Weld }\end{array}$ \\
\hline 1 & 700 & 240 & 235 & 195 & 190 \\
\hline 2 & 800 & 230 & 230 & 195 & 190 \\
\hline 3 & 750 & 245 & 235 & 200 & 195 \\
\hline 4 & 900 & 250 & 240 & 205 & 200 \\
\hline 5 & 1200 & 252 & 240 & 208 & 200 \\
\hline 6 & 1250 & 252 & 240 & 210 & 205 \\
\hline 7 & 1500 & 255 & 250 & 215 & 205 \\
\hline 8 & 1750 & 260 & 250 & 215 & 210 \\
\hline
\end{tabular}

The experiments are conducted in random order for the purpose of avoiding any bias and error. In order to optimize the process parameters for multiple quality characteristics, they have to be considered as a single quality characteristic, hence the use of modified Taguchi method [8]. The responses obtained through the experimentation are converted into a single response without attributing any units, but by adding weights to the responses. In this investigation average hardness on AISI304 side and tensile shear strength were given equal weightage. The weighted response computed is given in Table-5. 
Table 5: Weighted Response

\begin{tabular}{|c|c|}
\hline Run & Weighted Response \\
\hline $\mathbf{1}$ & 937 \\
\hline $\mathbf{2}$ & 1030 \\
\hline $\mathbf{3}$ & 990 \\
\hline $\mathbf{4}$ & 1145 \\
\hline $\mathbf{5}$ & 1445 \\
\hline $\mathbf{6}$ & 1495 \\
\hline $\mathbf{7}$ & 1752 \\
\hline $\mathbf{8}$ & 2005 \\
\hline
\end{tabular}

The hardness on austenitic stainless steel side is only considered since rate of increase of hardness is more than on ferritic stainless steel as exhibited in fusion and solid state welding processes [9]. The weighted response data are now subjected to analysis of Variance (ANOVA) and individual percentage contribution by each of the process parameter was also computed. The ANOVA of the weighted response was given in Table-6.

Table 6: ANOVA of weighted Response

\begin{tabular}{|c|c|c|c|c|c|}
\hline Parameter & $\begin{array}{c}\text { Sum of } \\
\text { SquaresX1000 }\end{array}$ & Dof & $\begin{array}{c}\text { Mean } \\
\text { squareX1000 }\end{array}$ & $\mathrm{F}$ & $\begin{array}{c}\% \\
\text { contribution }\end{array}$ \\
\hline $\mathbf{X}_{1}$ & 1626.8 & 1 & 1626.8 & 32.53 & 24.3 \\
\hline $\mathbf{X}_{2}$ & 2498.9 & 1 & 2498.9 & 49.97 & 37.3 \\
\hline $\mathbf{X}_{3}$ & 2366.4 & 1 & 2366.4 & 47.32 & 35.3 \\
\hline Error & 2001.2 & 4 & 50 & - & - \\
\hline Total & 6692.3 & 7 & - & - & - \\
\hline
\end{tabular}

The weighted responses by all the factors are computed and the results are plotted in Figure- 4 .

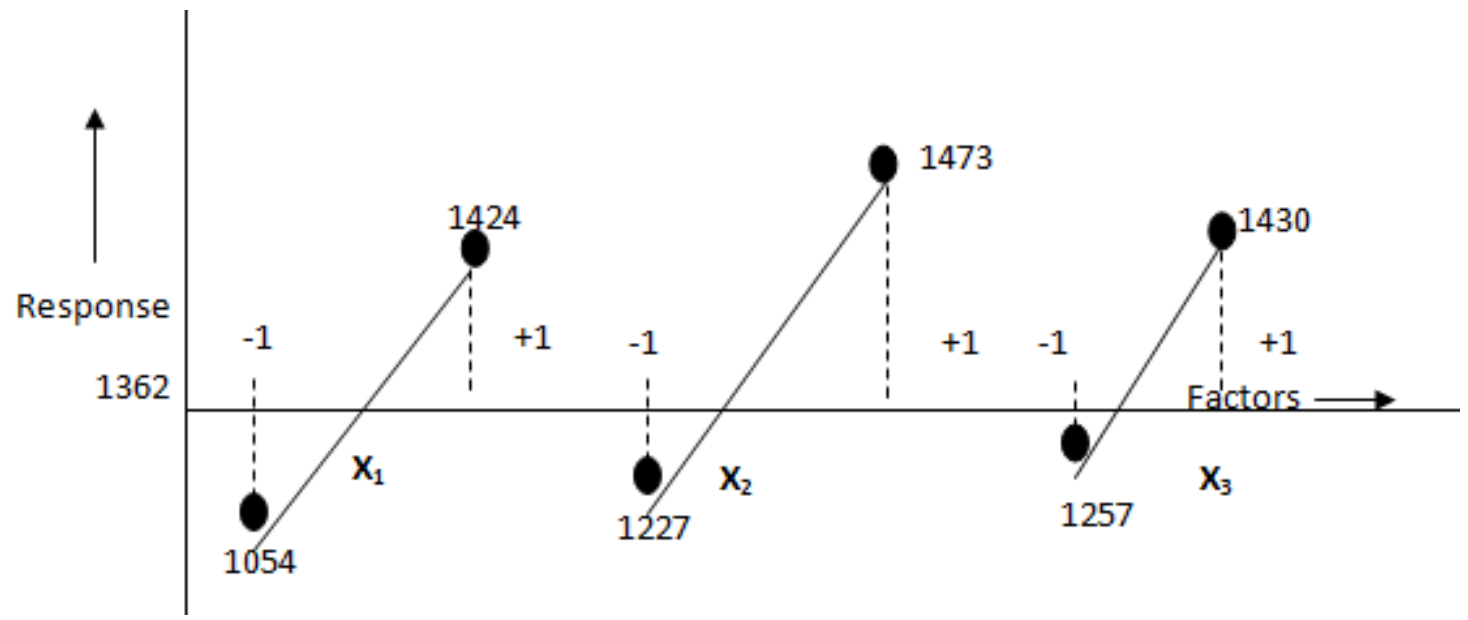

Figure 4: Response Graph

With the increase of weld current the rate of increase of tensile shear strength is greater than that of the hardness. The influence of weld time is larger than the other factors for the responses. In this the welding is performed on dissimilar stainless steels with different hardness and thermal condictivity values, so the electrode force has influenced greatly in getting the sound weld joint with largest tensile strength. The optimality condtion is found to be at higher levels for all the factors as given in Figure-4. Aconfirmation run is made to ascertain the validity of experimental results and proved that there is considerable improvement in multiple quality characterestics.

\section{Acknoweledgement}

The authors are thankful to Director and the correspondent of VJIT, Hyderabad for their support extended during this work.

\section{Refernces}

[1] F.B.Pickering "Physical metallurgy of Stainless steel Developments" International Metallurgical Revivew21,pp.227-268,1976

[2] E.R.Szymachowki, H.F.Reid " Cryogenic Toughness of SMA austenitic Stainless steel weld metals part1,role of ferrite" welding journal 57,1978
[3] A.Omer," Effects of welding parameters on hard zone formation at dissimilar metal welds, Welding journal,77 (2),86s-93s, 1998

[4] V.V.Satyanarayana, G.Madhusudhan Reddy, T.MohanDas "Dissimilar fiction welding of austeniticferritic stainless steels"journal of material Processing Technology,160,128-137,2005

[5] A.K.Pandey,M.I Khan,K.M.Moeed" Optimisation of resistance spot welding parameters using Taguchi method"International journal engineering science and technology,Vol-5.No.2,pp234-241,2013

[6] V.V.Satyanarayana, G.Madhusudhan Reddy, K.Veladri "Application of Modified Taguchi method in process parameter selection of shell molding process" Indian foundry journal,Vol-53,No.10,pp37-40,2007

[7] P.J.Ross" Taguchi techniques for Quality Engineering" $2^{\text {nd }}$ Ed,N.Y.Mcgraw hill,1996

[8] G.Taguchi," Introduction to Quality Engineering, Asian Productivity organistion",Tokyo,1990

[9] G.Madhusudhan Reddy "Influence of welding Process on micro structure and mechanical properties of dissimilar austenitic-ferritic stainless steels welds" International Journal of materials and Manufacturing Processes, Vol-20,pp147-173,2005 